\title{
Analisis Hubungan Corporate Social Responsibility (CSR)Terhadap Kinerja Keuangan Pada Perusahaan Jasa (Studi Kasus Perusahaan Jasa di D.I.Yogyakarta)
}

\author{
Oleh \\ Adeng Pustikaningsih ${ }^{1}$
}

\section{Latar belakang}

Tanggung jawab sosial perusahaan (Corporate Social Responsibility $=$ CSR) makin banyak memperoleh perhatian, terutama dalam beberapa dekade terakhir. Sebagai contoh, lebih dari 50 persen eksekutif global mengidentifikasi CSR sebagaiprioritas utama para eksekutif (The Economist, 2008). Lebih jauh, globalisasi ekonomi secara substansial meningkatkan tekanan pada perusahaan-perusahaan multinasional untuk mengatasi masalah tanggung jawab sosial (Smith, 2009) seperti rantai pasokan, perlindungan lingkungan, kondisi kerja, dan hak-hak karyawan (Mueller et al., 2009). Kegagalan untuk memenuhi harapan meningkatnya masyarakat global dapat membahayakan citra merek global dan reputasi, oleh karena itu, eksekutif memerlukan pemahaman lebih dalam tentang peran CSR.

Kegiatan CSR sebagian besar dilakukan berfokus pada stakeholder, yang berada di luar batas perusahaan, dengan demikian, kegiatan CSR pada umumnya, meningkatkan visibilitas perusahaan dan penyebaran goodwill dan reputasi untuk berbagai konstituen. Strategis aktivitas CSR yang didasarkan pada hubungan jangka panjang dengan masyarakat cenderung untuk mencapai pihak terkait dan memiliki dampak positif pada masyarakat.

Secara formal, ada perbedaan antara CSR dan CSP, namun dalam penelitian ini hanya membahas tentang CSR, dimana CSR adalah kegiatan perusahaan dan status yang berkaitan dengan kewajiban yang dirasakan masyarakat atau pemangku kepentingan (Brown dan Dacin, 1997; Sen dan Bhattacharya, 2001) sedangkan kinerja sosial perusahaan (CSP) adalah kinerja perusahaan secara keseluruhan dalam program CSR dalam kaitannya dengan mereka pesaing terkemuka di industri yang sama (Luo dan Bhattacharya, 2009). Sedangkan inisiatif CSR mencerminkan program perusahaan dan investasi dalam keberlanjutan, CSP merupakan penilaian stakeholder dari seluruh kualitas program-program dan investasi (Luo dan Bhattacharya, 2009; McWilliams dan Siegel, 2000).

Dalam hubungannya dengan kajian literatur hubungan antara CSR dan kinerja keunagan masih menunjukkan simpangsiur seperti bahwa tindakan CSR dapat mengakibatkan kinerja keuangan meningkat (Orlitzky et al, 2003; Chen, H, dan Wang, X. 2011), namun ada penelitian yang justru menghasilkan penelitian sebaliknya seperti Soana, M.G. (2011), dari sinilah penelitian ini berangkat.

\section{Teori dan pengembangan Hipotesis}

\section{Corporate Social Responsibility (CSR)}

Bila dilihat dari persepktif internal dan eksternal serta manajemen pemangku kepentingan, kegiatan CSR telah dilihat sebagai hal yang mempengaruhi stakeholder dalam perusahaan (Zagenczyk, 2004). Stakeholder dapat dilihat sebagai individu dan institusi yang dipengaruhi oleh tindakan perusahaan atau sekaligus kelambanan dalam dimensi temporal (mencakup masa lalu, masa kini dan masa depan) (Freeman, 1984; Langtry, 1994; Clarkson, 1995; Hopkins, 2003 ).

\footnotetext{
${ }^{1}$ Dosen Jurusan Pendidikan Akuntansi - Universitas Negeri Yogyakarta
} 
Stakeholder perusahaan bisa internal atau eksternal bagi perusahaan (Hopkins, 2003). Pemangku kepentingan intern adalah pemilik, manajer, karyawan dari suatu perusahaan, yang ada dalam batas perusahaan (Freeman, 1984; Polonsky, 1996). Sedangkan stakeholder eksternal dari suatu perusahaan adalah pemasok, pelanggan, masyarakat dan pemerintah (Freeman, 1984; Hopkins, 2003). Dari perspektif internal, melakukan kegiatan CSR diharapkan dapat memotivasi para karyawan dan menunjukkan praktek manajemen yang baik (suasana bagi pimpinan perusahaan dan karyawan) (Hill et al, 2003;. Royle, 2005). Dari perspektif eksternal melakukan kegiatan CSR perusahaan diharapkan untuk mendapatkan reputasi yang baik di masyarakat (termasuk pemerintah berbagai fungsionaris) dan juga membantu perusahaan untuk mengelola fungsinya agar lebih baik (terutama yang memiliki dimensi risiko yang terkait) (Lewis , 2003; Fombrun, 2005; Davis, 1960; Whetten et al, 2002;. Riordan et al, 1997).

Selanjutnya setiap organisasi yang memiliki kegiatan CSR secara strategis harus memiliki fokus jangka panjang (Osborn dan Hagedoorn, 1997; Boatright, 2000; Altman, 1998; Waddock, 2004). Hal ini juga berlaku untuk setiap kegiatan perusahaan lain yang memiliki konotasi strategis. Isue tentang sentralitas seperti ketika kegiatan CSR dimaksudkan untuk berkontribusi menuju terwujudnya visi, harus memiliki fokus jangka panjang. Setiap kegiatan yang bersifat strategis harus dapat membantu perusahaan untuk mencapai misi dan visinya. Dengan demikian, setiap kegiatan CSR yang strategis harus dekat dengan misi dan visi perusahaan (Yeoh, 2007; Du et al, 2007;. Bruch, 2005).

Selanjutnya setiap kegiatan CSR yang memiliki fokus jangka panjang akan memerlukan komitmen terhadap sumber daya besar (Russo dan Fouts, 1997; Porter dan Kramer, 2006; Branco dan Rodrigues, 2006). Hal ini karena untuk dalam tujuan jangka panjang, kegiatan perusahaan akan memerlukan pengorbanan dan dedikasi dari sejumlah besar sumber daya selama periode waktu tertentu.

Para penulis (Sze'kely dan Knirsch, 2005; Porter dan Kramer, 2006; Perrini, 2005; Crawford dan Scaletta, 2005) juga menunjukkan bahwa aktivitas CSR dapat:

(1) Membuat permintaan atas produk yang bertanggung jawab secara sosial dan ramah lingkungan dan jasa diantara konsumen dalam masyarakat dengan melakukan edukasi.

(2) Memberikan keterampilan teknis yang diperlukan kepada anggota masyarakat untuk mengembangkan, membuat dan menyempurnakan kemampuan teknis dari warga negara. Hal ini dapat dilakukan dengan mendirikan pendidikan, kejuruan, pelatihan dan lembaga pengetahuan.

(3) Bantuan pemerintah dan badan pemerintah untuk membingkai aturan dan peraturan untuk:

. mencegah perilaku buruk perusahaan khususnya pada kegiatan sosial dan lingkungan

. untuk mendorong perilaku perusahaan yang baik, untuk hal yang sama.

(4) Melestarikan sumber daya alam seperti air, bahan bakar fosil atau mengurangi emisi gas rumah kaca bagi negara lingkungan yang lebih baik dari kondisi pada semua tingkatan sehingga berbagai risiko lingkungan akan berkurang.

(5) Bantuan dalam mengembangkan kapasitas petani dan produsen bahan baku sehingga mereka dapat menyediakan perusahaan dengan bahan baku yang dibutuhkan berkualitas dan jumlah yang dibutuhkan.

(6) Bantuan untuk mengembangkan cluster industri dan dengan demikian membuat dan menambah dukungan infrastruktur bagi perusahaan.

Hubungannya dengan keuangan, setiap kegiatan perusahaan strategis harus membawa manfaat bisnis yang besar, pernyataan ini adalah pernyataan commonsensical dan tautologis. Keuntungan bisnis yang diwujudkan dalam cara yang berbeda, tetapi semua membantu perusahaan mencapai posisi kompetitif yang menguntungkan dan aman selama jangka waktu 
tertentu (keunggulan kompetitif yang berkelanjutan) (Sze'kely dan Knirsch, 2005; Porter dan Kramer, 2006; Perrini, 2005 ; Crawford dan Scaletta, 2005).

\section{Hubungan CSR dengan Kinerja Keuangan}

Makin banyak perusahaan yang merangkul konsep CSR, karena perusahaan-perusahaan yang merangkul dan mengimplementasikan Inisiatif CSR memiliki dampak positif pada pilihan yang dibuat oleh para pemangku kepentingan utama dalam perusahaan untuk memutuskan untuk memasuki hubungan dengan perusahaan, terutamakonsumen (del Mar Garcia de los Salmones, Crespo,\& Rodriguez del Bosque, 2005; Brown \& Dacin, 1997) dan potensi karyawan (Backhaus, Stone, \& Heiner, 2002; Greening \& Turban, 2000). Bahkan, Berens, van Riel, \& van Rekom, (2007) individu lebih memilih perusahaan yang secara aktif terlibat dalam inisiatif CSR yang berkaitan dengan perusahaan produk, saham. Ini yang dititikberatkan oleh Turban \& Greening (1997) yang mencatat bahwa perusahaan yang dianggap terlibat dalam Inisiatif CSR memiliki tingkat perputaran karyawan yang lebih rendah dibdaningkan mereka yang tidak terlibat dalam inisiatif tersebut, namun, secara umum, telah terjadi kurangnya konsensus mengenai hubungan antara perusahaan CSR inisiatif dan kinerja keuangannya. Inisiatif CSR dari sebuah perusahaan dan kinerja keuangan perusahaan adalah pengorbanan bisnis. Menurut gagasan ini, perusahaan yang terlibat dalam inisiatif CSR sebenarnya pada ekonomi yang mengalami kerugian dibdaningkan dengan tidak melakukan CSR, karena mereka dikenakan biaya untuk mengimplementasikan inisiatif tersebut (Aupperle, Carroll, \& Hatfield, 1985; Ullmann, 1985).

Hal ini senada dengan perusahaan telah melaporkan bahwa CSR memiliki inisiatif mengakibatkan kebocoran keuangan karena keuangan negatif kembali karena biaya tambahan memulai dan mendukung inisiatif CSR (McGuire, Sundgren, \& Schneeweis, 1988; Sen \& Bhattacharya, 2001). Sehingga hubungan antara CSR dan kinerja keuangan adalah memiliki hubungan yang lemah (surroca, 2010, Soana, 2011).

Di sisi lain, ada berpendapat bahwa melaksanakan inisiatif CSR akan bermanfaat karena dapat meningkatkan semangat kerja karyawan yang mengarah pada peningkatan produktivitas dan pada akhirnya peningkatan kinerja (McGuire et al., 1988).

Secara langsung CSR dapat memaksimalkan keseluruhan perusahaan nilai pasar (Mackey, Mackey, \& Barney, 2007) dan memiliki pengaruh positif pada nilai sekarang dari arus kas perusahaan(Godfrey, 2004). Secara tidak langsung, perusahaan yang terlibat dalam CSR akan mendapatkan keunggulan kompetitif di pasar terjadi melalui diferensiasi produk (McWilliams \& Siegel, 2001; (Waddock \& Graves, 1997), pengurangan atau penghapusan denda yang dikenakan pemerintah (Freedman \& Stagliano, 1991), sementara pada saat yang sama meminimalkannya risiko secara keseluruhan eksposur (Godfrey, 2004), karennya dalam penelitian oleh Sen dan Bhattacharya (2001) menunjukkan bahwa inisiatif CSR perusahaan memiliki pengaruh positif pada pelanggan (Sen dan Bhattacharya, 2001), yang akhirnya aktivitas tanggung jawab sosial perusahaan dapat meningkatkan kinerja keuangan (Chen, Honghui, dan Wang, X., 2011)

Sehingga dalam penelitian ini, hipotesis yang diajukan adalah "terdapat hubungan yang positif antara karakteristik CSR dengan karakteristik kinerja keuangan”

\section{Metode Penelitian}

Penelitian ini menggunakan Structural Equation Modeling (SEM) dengan software AMOs versi 16. Dimana terdapat dua variabel konstruk yang keduanya menggunakan skala likert 5 point dimana 1 menunjukkan sangat rendah dan 5 menunjukkan sangat tinggi. 


\section{Pengukuran Variabel Penelitian}

Dalam penelitian ini, pengukuran yang digunakan dalam CSR adalah dengan menggunakan Mahoney dan Roberts(2007)yaitu :

1. Isu komunitas (IK)

2. Keragaman tempat kerja (KT)

3. Hubungan tenaga kerja (HT)

4. Kinerja lingkungan (KL)

5. Internasional (I)

6. Produk dan praktek bisnis (PB)

sementara itu kinerja keangan menggunakan Chan (2006), dimana kategori yang digunakan adalah :

1. Profitabilitas(Profit) -ROE dan ROS

2. Assets Utilization (AU) - ROA

3. Pertumbuhan $(\mathrm{G})-\%$ perubahan assets, $\%$ perubahan sales, $\%$ perubahantenaga kerja untuk 3-5 tahun yang lalu.

4. Liquiditas (L) - Cash Flow, Acid Test dan Pay Out Ratios

5. Resiko Pasar (RP).

\section{Responden dan Pengumpulan Data}

Responden penelitian ini adalah 148 perusahaan jasa yang ada di D.I Yogyakarta yang mana kuisioner diisi oleh para CEO perusahaan tersebut, Pengiriman kuisioner dilakukan dengan surat pos dan yang kembali ada 100 kuisioner, sehingga respon rate-nya $68 \%$.

\section{Model Penelitian}

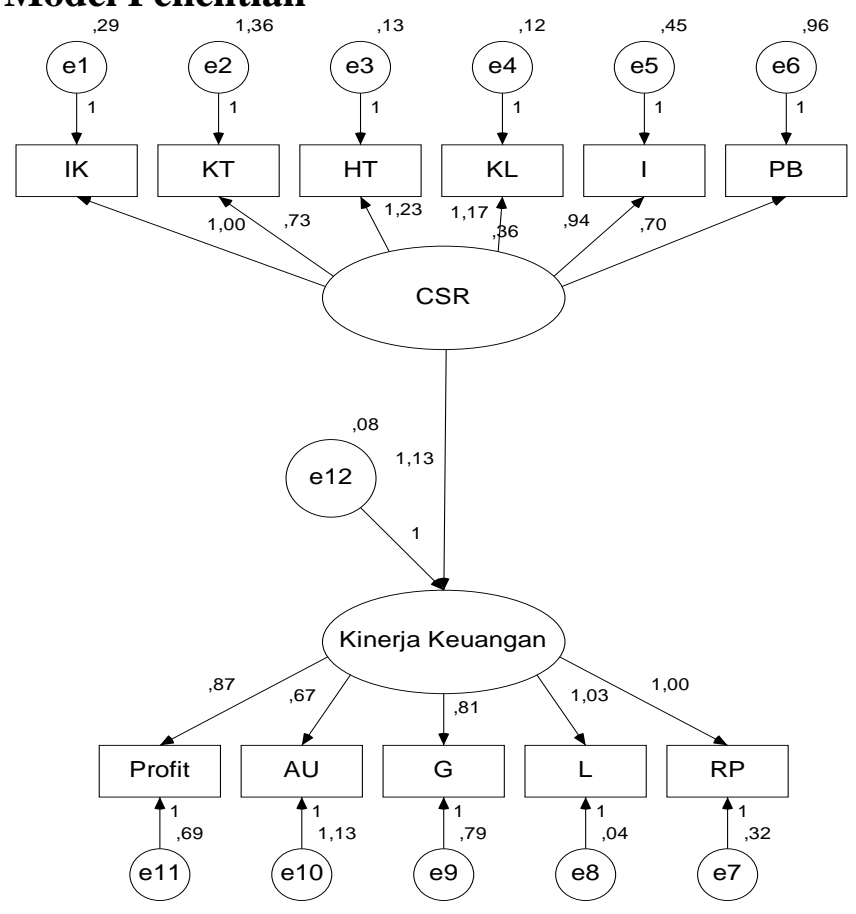

\section{Hasil Penelitian}

Tes reliability pada semua variabel konstruk pada keseluruhan model menunjukan cronbach alfa sebesar 0,734 sehingga sangat fit karena diantara 0,8-0,9. Dimendi variabel CSR dengan menggunakan metode Confirmatory Factor Analysis (CFA) menunjukkan model yang fit dimana $\chi 2=6,049, \mathrm{df}=9, \mathrm{p}$-value $=0.00, \mathrm{GFI}=0.858, \mathrm{RMSEA}=0.239$, sedangkan dimensi 
variabel Kinerja Keuangan juga menunjukkan fit model dengan $\chi 2=3,531$, df $=5$, p-value $=$ $0.00, \mathrm{GFI}=0.898, \mathrm{RMSEA}=0,232$.

Tabel 1

Signifikansi antar Variabel

\begin{tabular}{|c|c|c|c|c|c|c|c|}
\hline & & & Estimate & S.E. & C.R. & $\mathrm{P}$ & Label \\
\hline Kinerja Keuangan & $\begin{array}{ll}<-- \\
-\end{array}$ & CSR & 1,127 & 149 & 7,553 & $* * *$ & \\
\hline $\mathrm{IK}$ & $<--$ & CSR & 1,000 & & & & \\
\hline $\mathrm{KT}$ & $<---$ & CSR &, 733 & ,212 & 3,461 & $* * *$ & \\
\hline HT & $<---$ & CSR & 1,235 &, 132 & 9,390 & $* * *$ & \\
\hline KL & $<---$ & CSR & 1,175 & ,125 & 9,431 & $* * *$ & \\
\hline I & $<---$ & CSR & ,945 &, 146 & 6,493 & $* * *$ & \\
\hline PB & $<---$ & CSR & ,697 &, 181 & 3,855 & $* * *$ & \\
\hline $\mathrm{RP}$ & $<---$ & Kinerja Keuangan & 1,000 & & & & \\
\hline $\mathrm{L}$ & $<---$ & Kinerja Keuangan & 1,028 & ,090 & 11,387 & $* * *$ & \\
\hline G & $<---$ & Kinerja Keuangan & ,808 & ,139 & 5,800 & $* * *$ & \\
\hline $\mathrm{AU}$ & $<---$ & Kinerja Keuangan & ,666 &, 157 & 4,240 & $* * *$ & \\
\hline Profit & $<--$ & Kinerja Keuangan & ,869 & ,134 & 6,469 & $* * *$ & \\
\hline
\end{tabular}

\section{Kesimpulan}

Secara keseluruhan dengan model SEM akhirnya dapat diketahui bahwa model sudat FIT, dimana $\chi 2=26,3$, df $=43$, p-value $=0.00$, GFI $=0.697$, RMSEA $=0.231$, sehingga hasil penelitian ini menunjukkan bahwa CSR berhubungan dengan Kinerja Keuangan dengan probabilitas $1 \%$ (lihat tabel 1), sehingga hipotesis dalam penelitian penelitian ini yang menunjukkan bahwa terdapat hubungan yang positif antara karakteristik CSR dengan karakteristik Kinerja Kauangan dapat diterima.

\section{Saran Penelitian yang Akan Datang}

Walaupun model penelitian ini sudah FIT namun peneliti menyarankan ada peran moderasi atau mediasi dalam penelitian tersebut, karena model CSR dengan kinerja keuangan memiliki pengaruh yang tidak langsung (John P. dan Lisa P., 2008), sehingga dibutuhkan hubungan yang tidak langsung tersebut dengan variabel lain baik mediasi maupun moderasi.

\section{DAFTAR PUSTAKA}

Altman, B.W. (1998), "Transformed corporate community relations: a management tool forachieving corporate citizenship", Business and Society Review, Vols 102/103, 43-51.

Aupperle, K., Carroll, A., \& Hatfield, J. (1985). An empirical examination of the relationship between corporate social responsibility andprofitability. Academy of Management Journal, 28, 446-463.

Backhaus, K. B., Stone, B. A., \& Heiner, K. (2002). Exploring the Relationship between Corporate Social Performance and EmployerAttractiveness. Business \& Society, 41(3), 292-318.

Berens, G., Van Riel, C. B., \& Van Rekom, J. (2007). The CSR-Quality Trade-Off: When can Corporate Social Responsibilityand Corporate Ability Compensate Each Other? Journal of Business Ethics, Spring (74), 233-252. 
Boatright, J.R. (2000), Ethics dan the Conduct of Business, Prentice-Hall, Upper Saddle River, NJ.

Branco, M. dan Rodrigues, L. (2006), "Corporate social responsibility and resource-based perspectives", Journal of Business Ethics, Dordrecht, Vol. 69 (2), 111-143.

Brown, T. J., \& Dacin, P. A. (1997, January). The Company dan Product: Corporate Associations and Consumer Product Responses.Journal of Marketing, 61(January), 68-84.

Brown, T.J. dan Dacin, P.A. (1997), "The company dan theproduct: corporate associations dan consumer productresponse", Journal of Marketing, Vol. 61, pp. 68-84.

Bruch, H. (2005), "The keys to rethinking corporate philanthropy", MIT Sloan ManagementReview, Vol. 47 (1), 49-59.

Chdan, Masud, (2006). The Relationship between Corporate Social Performance and Corporate Financial Performance: Industry tipes as a boundary Condition, The Business Review, Cambridge, Vol. 5 (1), 240-245.

Chen, Honghui, dan Wang, Xiayang, (2011). Corporate social responsibility dan corporate financial performance in China: an empirical research from Chinese firms, Corporate Governance: The International Journal of Effective Board Performance, Vol. 11 (4), 361-370

Clarkson, M.B.E. (1995), "A stakeholder framework for analyzing and evaluating corporate socialperformance", Academy of Management Review, Vol. 20(1), 92-117.

Crawford, D. dan Scaletta, T. (2005), "The balanced scorecard and corporate social aligningscorecard dan corporate social aligning values", CMA Management, Vol. 79(6), 20-27.

Davis, K. (1960), "Can business afford to ignore social responsibilities?", California Management Review, Vol. 2(3), 70-76.

Del Mar Garcia de los Salmones, M. A., Crespo, H., \& Rodriguez del Bosque, I. (2005). Influence of Corporate Social Responsibility onLoyalty dan Valuation Services. Journal of Business Ethics, 61(4), 369-385.

$\mathrm{Du}$, S., Bhattacharya, C.B. dan Sen, S. (2007), "Reaping relational rewards from corporate socialresponsibility: the role of competitive positioning", International Journal of Research inMarketing, Vol. 24 (3), 224-265.

Fombrun, C.J. (2005), "RI insights a world of reputation research, analysis and thinking buildingcorporate reputation through csr initiatives: evolving stdanards", Corporate ReputationReview, Vol. 8 (1), 7-11.

Freedman, M., \& Stagliano, A. J. (1991). Differences in social cost disclosures: A market test of investor relations. Accounting, Auditingand Accountability Journal, 4 (1), 6883.

Freeman, R.E. (1984), Strategic Management: A Stakeholder Approach, Pitman, Marshfield, MA.

Godfrey, P. C. (2004). The Relationship between corporate philanthropy and shareholder wealth: A risk management perspective. Academy of Management Review, 30, 777-798.

Greening, D. W., \& Turban, D. B. (2000). Corporate Social Performance as a Competitive Advantage in Attracting a QualityWorkforce. Business \& Society, 3 (September), 254-280.

Hill, R.P., Stephens, D. dan Smith, I. (2003), “Corporate social responsibility: an examination ofindividual firm behavior”, Business dan Society Review, Vol. 108 (3), pp. 339403.

Hopkins, M. (2003), "Why corporate social responsibility?", The Planetary Bargain CorporateSocial Responsibility Matters, Earth Scan, London. 
Langtry, B. (1994), "Stakeholders dan the moral responsibilities of business", Business EthicsQuarterly, Vol. 4 (4), 431-473.

Lewis, S. (2003), "Reputation dan corporate responsibility", Journal of CommunicationManagement, Vol. 7 (4), 356-420.

Luo, X. dan Bhattacharya, C.B. (2009), "The debate overdoing good: corporate social performance, strategicmarketing levers and firm-idiosyncratic risks", Journal of Marketing, Vol. 73 No. 6, pp. 198-213.

Mackey, A., Mackey, T. B., \& Barney, J. B. (2007). Corporate Social responsibility dan Firm Performance: Investor Preferences andCorporate Strategies. Academy of Management Review, 3(32), 817-835.

Mahoney, L S dan Roberts, R W (2007). "CorporateSocial Performance, Financial Performance andInstitutional Ownership in Canadian Firms". AccountingForum, 31(3), 233-253.

McGuire, J. B., Sundgren, A., \& Schneeweis, T. (1988). Corporate Social Responsibility and Firm Financial Performance. Academy ofManagement Journal, 31(4), 854-872.

McWilliams, A. dan Siegel, D. (2000), "Corporate socialresponsibility dan financial performance: correlation ormisspecification”, Strategic Management Journal, Vol. 21 (5), 603-9.

Mueller, M., dos Santos, V.G. dan Seuring, D. (2009), "Thecontribution of environmental and social stdanards towardsensuring legitimacy in supply chain governance", Journal of Business Ethics, Vol. 89(4),509-23.

Orlitzky, M., Schmidt, F.L. dan Rynes, S. (2003), "Corporatesocial dan financial performance: a meta analysis",Organization Studies, Vol. 24 (3), 403-444.

Osborn, R.N. dan Hagedoorn, J. (1997), "The institutionalization and evolutionary dynamics ofinterorganizational alliance dan networks", The Academy of Management Journal, Vol. 40 (2), 261-339.

Perrini, F. (2005), "Building a European portrait of corporate social responsibility reporting", European Management Journal, Vol. 23 (6), 611-638.

Polonsky, M.J. (1996), "Stakeholder management and the stakeholder matrix: potential strategicmarketing tools", Journal of Marketing-Focused Management, Vol. 1, 209-238.

Porter, M.E. dan Kramer, M.R. (2006), "Strategy \& society: the link between competitive advantagedan corporate social responsibility", Harvard Business Review, Vol. 84(12), 56-68.

Riordan, C.M., Gatewood, R.D. dan Bill, J.B. (1997), "Corporate image: employee reactions andimplications for managing corporate social performance", Journal of Business Ethics, Vol.16, 401-413.

Royle, T. (2005), "Realismor idealism? Corporate social responsibility and the employee stakeholderin the global fast-food industry", Business Ethics:A European Review, Vol. 14 (1), 42-55.

Russo, M. dan Fouts, P. (1997), "A resource-based perspective on corporate environmentalperformance and profitability", Academy of Management Journal, Vol. 40 (3), 534-593.

Sen, S. dan Bhattacharya, C.B. (2001), "Does doing goodalways lead to doing better? Consumer reactions tocorporate social responsibility", Journal of MarketingResearch, Vol. 38, 225-269.

Smith, N.C. (2009), "Bounded goodness: marketingimplications of Drucker on corporate socialresponsibility", Journal of Academy of Marketing Science, Vol. 37, 73-84. 
Soana, Maria Gaia., (2011). The Relationship Between Corporate Social Performance and Corporate Financial Performance in the Banking Sector, Journal of Business Ethics, Vol. 104 (1), 133-148

Surroca Jordi, Tribó, Josep, dan Waddock, Sdanra, (2010). Corporate responsibility and financial performance: the role of intangible resources, Strategic Management Journal, Vol. 31 (5), 463-490.

Sze'kely, F. dan Knirsch, M. (2005), "Responsible leadership and corporate social responsibility: metricsfor sustainable performance", European Management Journal, Vol. 23 (6), 628-47.

The Economist (2008), "Just good business", The Economist, 17 January.

Turban, T. D., dan Greening, D. W. (1997). Corporate Social Performance and Organizational Attractiveness to prospective employees.Academy of Management Journal, 40 (3), 658-672.

Ullmann, A. (1985). Data in search of a theory: A critical examination of the relationships among social performance, social disclosure, and economic performance. Academy of Management Review, 10, 540-577.

Waddock, S. (2004), "Parallel universes: companies, academics, and the progress of corporatecitizenship", Business dan Society Review, Vol. 109(1), 5-42.

Waddock, S. A., dan Graves, S. B. (1997). The Corporate Social Performance Link. Strategic Management Journal, 18, 303-319.

Whetten, D.A., Rdans, G. dan Godfrey, P. (2002), "What are the responsibilities of business tosociety?", in Pettigrew, A.M., Howard, T. dan Whittington, R. (Eds), Hdanbook of Strategydan Management, Sage, London, pp. 373-409.

Yeoh, P. (2007), "The direction and control of corporations: law or strategy?", Managerial Law, Vol. 49, 1/2.

Zagenczyk, T.J. Jr (2004), "Using social psychology to explain stakeholder reactions to anorganization's social performance", Business dan Society Review, Vol. 109 (1), pp. 97-101.

John P. dan Lisa P., (2008). The Missing Link between Corporate SocialResponsibility dan Financial Performance:Stakeholder Salience and Identifi cation, Corporate Reputation Review, Vol. 11, (2), 169-181. 